\title{
Incorporation of Clathrochelate-Based Metalloligands in Metal-Organic Frameworks by Solvent-Assisted Ligand Exchange
}

\author{
Ophélie M. Planes," Pascal A. Schouwink,, José L. Bila," Farzaneh Fadaei-Tirani,", Rosario Scopelliti" and \\ Kay Severin*,\# \\ \# Institute of Chemical Sciences and Engineering, Ecole Polytechnique Fédérale de Lausanne (EPFL), CH-1015 Lausanne and \\ CH-1951 Sion, Switzerland
}

\begin{abstract}
Iron(II) cage complexes with terminal 4-pyridyl groups can be incorporated in metal-organic frameworks (MOFs) via solventassisted ligand exchange (SALE). Paddle-wheeled MOFs with N,N'-di-4-pyridylnaphtalenetetracarboxydiimide pillars were used as starting materials. Pillar exchange was nearly quantitative, despite the fact that the cage complexes are long ( $15 \AA ̊)$ and sterically demanding. The reactions provide products of high crystallinity, and the structures of daughter MOFs were determined by single crystal X-ray diffraction. The crystallographic analyses showed that some of the SALE experiments led to topological changes of the MOF structures.
\end{abstract}

The synthesis of novel metal-organic frameworks (MOFs) can be accomplished by postsynthetic modification of existing framework structures. ${ }^{1}$ This approach provides MOFs with identical topologies, but with new properties, which can be advantageous for applications. Work in this area has primarily focused on the alteration of organic linkers by chemical means. Successful heterogeneous reactions of MOF linkers include condensation-, addition-, and deprotection reactions, as well as oxidation and reduction reactions, among others. ${ }^{1}$

An interesting alternative to the chemical modification of organic linkers is the complete replacement of one type of linker within a MOF by a new one. ${ }^{1 a, b, 2,3}$ This process is referred to as 'solvent-assisted linker exchange' (SALE) ${ }^{2 b}$ or postsynthetic exchange (PSE) (Scheme 1). ${ }^{2 b}$ The first demonstration that SALE can be used to replace bridging ligands in 2- and 3-dimensional MOFs was reported in 2011 by the group of Choe. ${ }^{4}$ As starting materials, they have used pillared paddle-wheel MOFs constructed from tetrakis(4-carboxyphenyl)porphyrin (TCPP), N,N'-di-4-pyridylnaphtalenetetracarboxydiimide (DPNI) linkers, and $\mathrm{Zn}_{2}\left(\mathrm{O}_{2} \mathrm{C}\right)_{4}$ metal nodes. When the MOFs were suspended in solutions containing 4,4'-bipyridine, a complete replacement of the DPNI pillars with the smaller bipyridine was observed. Despite a strong reduction of the layer-to-layer distance, the MOFs retained their crystallinity, and the products could be characterized by single crystal $\mathrm{X}$-ray diffraction.

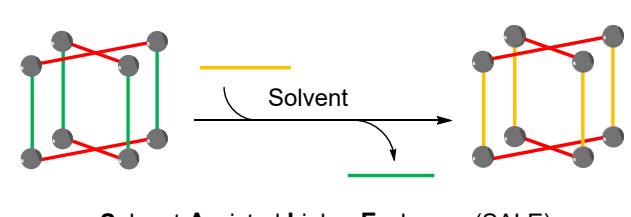

Solvent-Assisted Linker Exchange (SALE)

Scheme 1. Schematic illustration of the SALE technique for a representative MOF structure.

Following this seminal report by Choe and co-workers, the SALE technique has been used for the synthesis of numerous other
MOF structures, many of which are not accessible by standard solvothermal reactions. ${ }^{1 a, b, 2}$, In addition to exchange reactions of bipyridyl ligands, ${ }^{4-6}$ linker exchange was demonstrated for carboxylate, ${ }^{7}$ imidazolate, ${ }^{7 i, 8}$ and triazolate ligands. ${ }^{9}$ These studies also revealed potential problems of the SALE methodology. Incomplete ligand exchange was encountered, even after prolonged reaction times. Moreover, the quality of the crystals tends to degrade during SALE, often preventing single crystal X-ray diffraction analysis of the daughter materials. . $^{4}$

Boronate ester-capped iron cage complexes ('clathrochelate complexes') ${ }^{10}$ represent interesting building blocks for applications in supramolecular coordination chemistry. ${ }^{11}$ These cage complexes can be synthesized in one step from readily available starting materials. Importantly, they can be decorated with different functional groups, including metal-binding donor groups. For example, it is possible to prepare clathrochelates with two or more pyridyl groups, which are oriented in a divergent fashion. While these pyridyl-capped complexes turned out to be valuable components for the construction of molecularly defined nanostructures, ${ }^{11,12}$ we had only limited success in using them for MOF synthesis. ${ }^{13}$

In a recent study, we noticed that iron cages complexes with terminal pyridylboronate ester groups are more basic than standard pyridyl ligands. ${ }^{14}$ The high proton affinity of these metalloligands is likely related to the presence of the boronate ester group, which has a formal negative charge. Highly basic pyridyl ligands are expected to be well suited for SALE experiments. ${ }^{5 j}$ Therefore, we have explored the possibility to incorporate iron cage complexes in MOFs using ligand exchange reactions instead of solvothermal reactions. The SALE technique indeed allowed synthesizing MOFs containing clathrochelate complexes. Notably, the quality of the daughter crystals was sufficient for single crystal XRD analyses. The results of our investigations are summarized below.

First, we examined ligand exchange reactions using a paddlewheel MOF containing a tetracarboxylic acid ligand and DPNI pillars (MOF 1, Scheme 2). The synthesis of MOF 1 was described by Hupp and co-workers. ${ }^{15}$ The bromo substituents on the carboxylate ligand prevent interpenetration. Consequently, 1 features 
large pores, which were expected to facilitate ligand exchange with sterically demanding clathrochelate complexes.

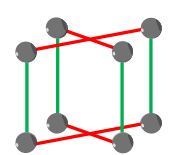

1
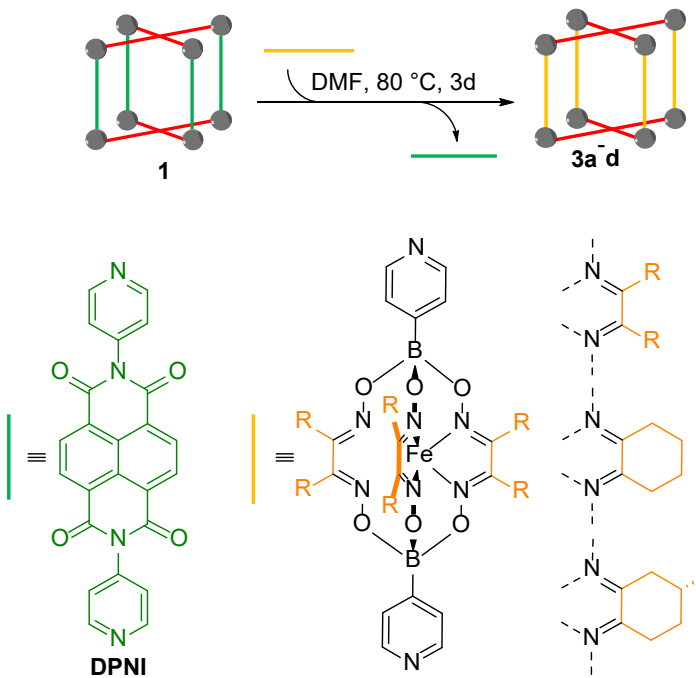

(R=Et)

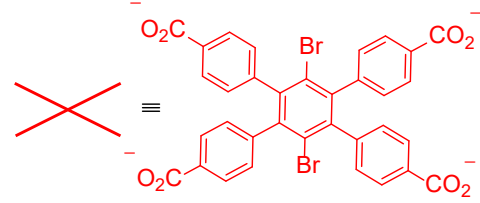

$\equiv \mathrm{Zn}_{2}\left(\mathrm{O}_{2} \mathrm{C}\right)_{4}$

Scheme 2. Synthesis of the MOFs 3a-d.

For SALE experiments with $\mathbf{1}$, we have used the pyridylcapped cage complexes $\mathbf{2 a - d}$ (Scheme 2 ). The complexes were prepared from 4-pyridylboronic acid, $\mathrm{FeCl}_{2}$ and the corresponding dioxime in analogy to reported procedures. ${ }^{13,16}$ It is worth noting that $\mathbf{2} \mathbf{d}$ features a chiral side chain, because the dioxime is derived from $(R)$-Pulgeone.

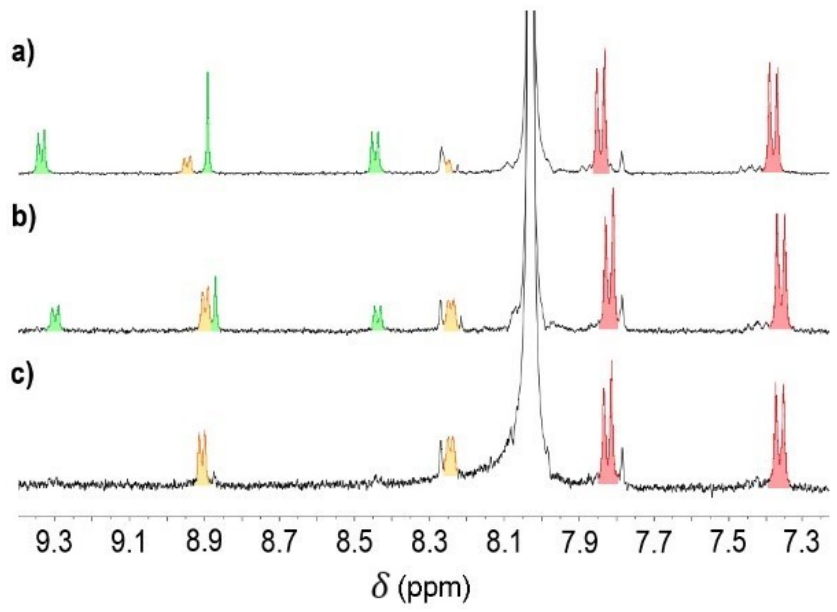

Figure 1. Progress of the conversion of $\mathbf{1}$ into $\mathbf{3 d}$ as monitored by ${ }^{1} \mathrm{H}$ NMR spectroscopy (DMSO- $\mathrm{d}_{6}+\mathrm{H}_{2} \mathrm{SO}_{4}$, zoom on the aromatic region). Sample composition after 1 day (a), after 2 days (b), and after 3 days (c). Signals depicted in green correspond to the protonated DPNI linker, orange for the protonated clathrochelate $\mathbf{2 d}$, and red for the carboxylic acid ligand.
Crystalline 1 was prepared as described by Hupp and co-workers. ${ }^{15}$ The phase purity was verified by powder XRD (SI, Figure S14). Ligand exchange was then initiated by suspending crystals of $\mathbf{1}$ in a DMF solution of 2 . The mixture was heated to $80^{\circ} \mathrm{C}$, and progress of the reaction was monitored by UV-Vis (SI, Figure S10) and NMR spectroscopy (prior to NMR analysis, the MOF structure was disrupted by addition of $\mathrm{H}_{2} \mathrm{SO}_{4}$, Figures $\mathrm{S} 5-\mathrm{S} 7$ ). Clean pillar exchange was observed for all four cage complexes. Even for the sterically demanding complex $\mathbf{2 d}$, we observed nearly quantitative ligand exchange after 3 days (Figure 1). We have also attempted to prepare MOFs of type $\mathbf{3}$ using standard solvothermal reaction conditions, but we were unable to obtain crystalline products.

The phase-purity of 3a-d was established by powder XRD (SI, Figures S15-S18). Interestingly, the crystal quality was largely preserved during ligand exchange (Figure 2). We were therefore able to perform single crystal X-ray analyses of the products $\mathbf{3 a}$ and $\mathbf{3 d}$ (Figure 3). a)

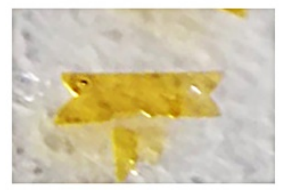

b)

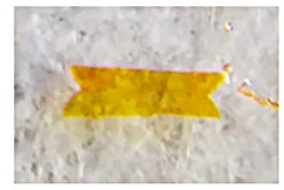

Figure 2. Photographs of a crystal of 1 before (a) and after (b) immersion into a DMF solution of $\mathbf{2 a}$ for 5 days at RT. a)

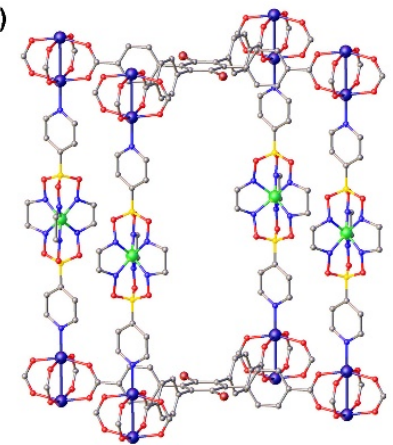

c)

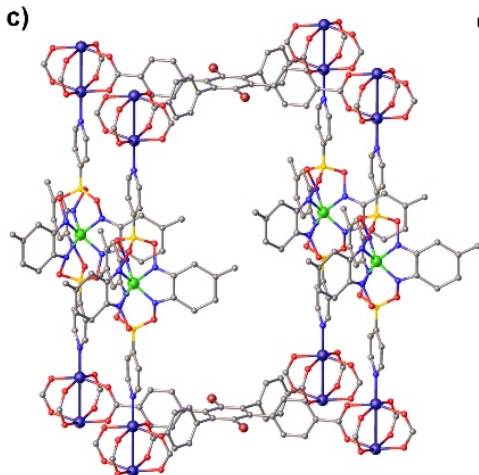

b)

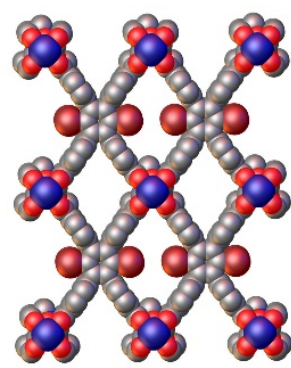

d)

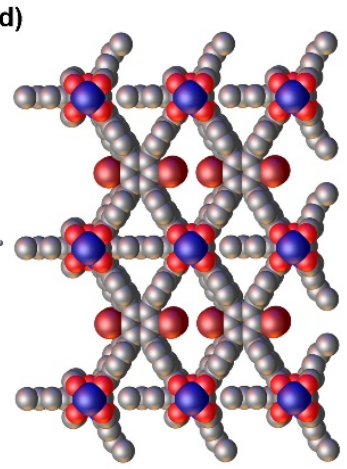

Figure 3. Part of the molecular structure of $3 a(a$ and $b$ ) and $3 d$ (c and d) in the crystal. Color coding: $\mathrm{C}$ (gray), Fe (green), Zn (dark blue), O (red), B (yellow), N (blue), Br (brown).

Retention of the parent MOF topology ( $P$ mmm space group) was found for both cases. However, slightly reduced interlayer distances were observed as a consequence of the shorter lengths 
of $\mathbf{2} \mathbf{a}$ and $\mathbf{2 d}$ when compared to DPNI. The length of the dipyridyl pillars is linked to unit cell parameter $c$, which is decreasing from

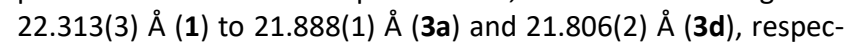
tively. The increased steric demand of $\mathbf{2 d}$ leads to a reduced solvent-accessible volume for $\mathbf{3 d}\left(2332.5 \AA^{3}\right)$ when compared to $\mathbf{3 a}$ $\left(2974.9 \AA^{3}\right)$. The clathrochelate pillars in 3a and 3d are highly disordered, indicating conformational flexibility around the pillar axis. Based on the size of the central iron complex, one would assume a largely unhindered rotation for pillar $\mathbf{2 a}$ in MOF $\mathbf{3 a}$. For $\mathbf{3 d}$, however, the clathrochelate side chains are interdigitated (Figure $3 \mathrm{~d}$ ), and correlated ligand movements are expected.

Next, we investigated if pyridyl-capped clathrochelate complexes can be incorporated into pillared MOFs with porphyrinbased carboxylate ligands. SALE experiments were performed with a 2-dimensional MOF termed 'PPF-18' (MOF 4, Scheme 3), which was reported by the group of Choe. ${ }^{17}$ It features layers composed of $\mathrm{Zn}_{2}\left(\mathrm{O}_{2} \mathrm{C}\right)$ nodes and metallated tetrakis(4-carboxyphenyl)porphyrin (TCPP-Zn) ligands. The layers are connected in a pair-wise fashion via DPNI pillars to give a double-layer structure. Each pillar coordinates to one $\mathrm{Zn}_{2}\left(\mathrm{O}_{2} \mathrm{C}\right)$ node and to one $\mathrm{Zn}$ porphyrin, resulting in an $A B$ stacking pattern of the layers.

When crystals of 4 (PPF-18) were immersed in a concentrated DMF solution of metalloligand $\mathbf{2 a}$, we were able to observe complete pillar exchange after heating to $80^{\circ} \mathrm{C}$ for 3 days (Scheme 3). ${ }^{18}$ An NMR analysis of the digested product showed that the new MOF structure $\mathbf{5}$ displayed an increased pillar content of 2a:TCPP-Zn = 3:1 (SI, Fig. S8). For comparison, the corresponding ratio for $\mathbf{4}$ is DPNI:TCPP-Zn: $=1: 1$. The presence of additional pillars in $\mathbf{5}$ suggested cross-linking of the double layers. Analysis of 5 by single crystal XRD confirmed that a 3-dimensional MOF had formed. Unfortunately, we were only able to obtain diffraction data of poor quality, and we therefore refrain from discussing structural details. Nevertheless, the topology of $\mathbf{5}$ could clearly be established (SI, Fig. S23), and a schematic representation of the structure is depicted in Scheme 3 . In contrast to what was found for $\mathbf{4}$, the $\mathrm{Zn}_{2}\left(\mathrm{O}_{2} \mathrm{C}\right)$ nodes in $\mathbf{5}$ are linked to two pillars, resulting in an overall ABBA stacking pattern. It is worth noting that a similar topology change from $2 D$ to $3 D$ was observed when SALE experiments were performed with PPF-19 and an excess of 4,4'-bipyridine. ${ }^{4}$ However, a cross-linking of layers was not successful with larger DPNI pillars. ${ }^{19}$

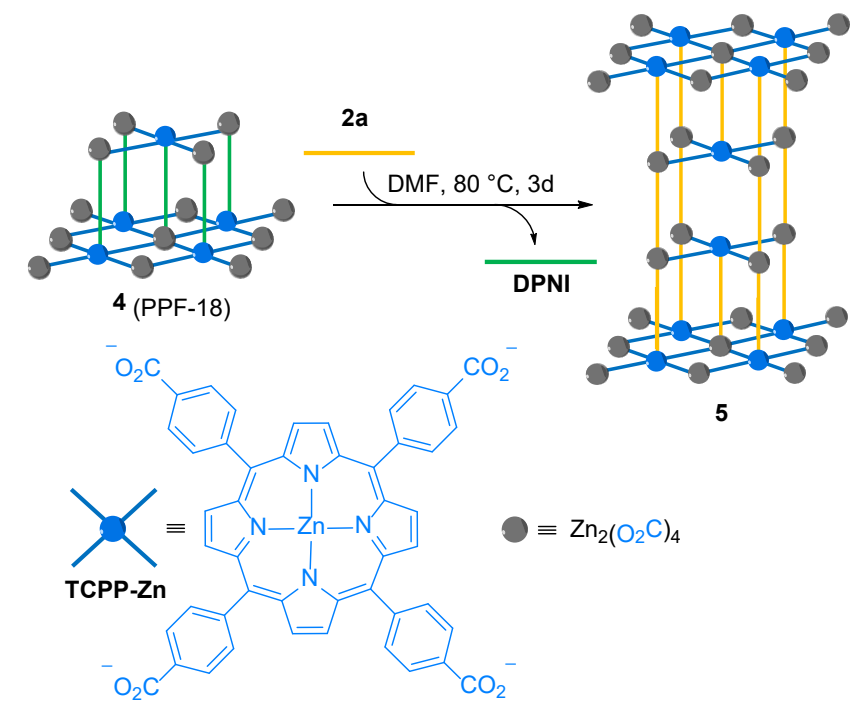

Scheme 3. Synthesis of MOF 5.
Finally, we have investigated pillar exchange using a TCPP-Znbased MOF termed 'PPF-19' (MOF 6, Scheme 4). PPF-19 is doubly interpenetrated and we anticipated that the SALE process would be impeded by the reduced pore size. However, this prediction turned out to be wrong, and clean pillar exchange was observed when crystalline 6 was heated in a solution of $2 a$ in DMF (Scheme 4). ${ }^{18}$

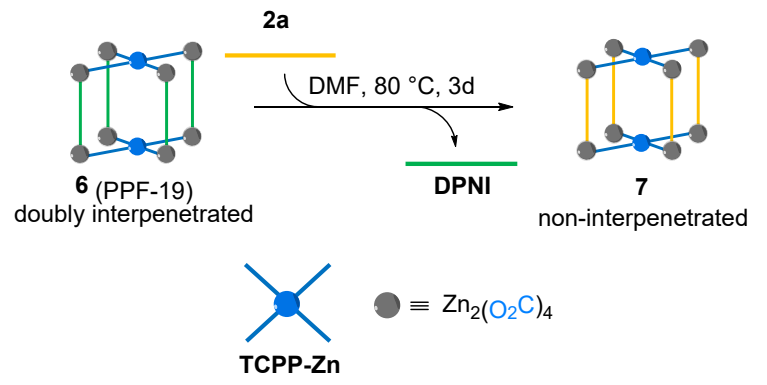

Scheme 4. Synthesis of MOF 7.

As observed for the other reactions, the SALE process led only to a partial degradation of crystal quality. We were therefore able to perform a single crystal XRD analysis of MOF 7. As in the case of $\mathbf{5}$, we did not manage to obtain high quality diffraction data. The problem is in part related to the fact that the metalloligand in 7 is highly disordered (SI, Fig. S24). In view of these difficulties, we do not discuss any structural details. However, the topology of 7 could clearly be established. The connectivity of $\mathbf{7}$ is identical to that of 6: Each $\mathrm{Zn}_{2}\left(\mathrm{O}_{2} \mathrm{C}\right)$ node is coordinated to four TCPP-Zn ligands and to two dipyridyl pillars $2 \mathrm{a}$. The $\mathrm{Zn}$ porphyrin complexes are not involved in binding to the $\mathrm{N}$-donor ligands. In contrast to what was found for $\mathbf{6}$, there is no interpenetration in the network structure of 7. As a result, we observe large voids, with a solventaccessible volume of approximately $4794.2 \AA^{3}$. Unfortunately, attempts to obtain a material with permanent porosity failed. Network collapse was observed upon removal of the solvent.

The change in topology from $\mathbf{6}$ to $\mathbf{7}$ is likely related to the increased steric demand of the metalloligand $2 \mathrm{a}$ when compared to DPNI. From a mechanistic point of view, the conversion of an interpenetrated structure into a non-interpenetrated daughter structure is intriguing, in particular since we were able to obtain single crystals of the product. A dissolution-recrystallization process appears to be a likely scenario for the formation of $\mathbf{7}$ (and possibly also for $\mathbf{3}$ and $\mathbf{5}$ ), but further investigations would be needed to clarify this point.

To conclude, we have shown that clathrochelate-based metalloligands with terminal 4-pyridyl groups can be incorporated in pillared paddle-wheel MOFs by using the SALE technique. Pillar exchange was found to be nearly quantitative, despite the fact that the metalloligands are long $(\sim 15 \AA)$ and sterically demanding. We assume that the exchange process is facilitated by the high basicity of the metalloligands, which should lead to more stable metal-ligand interactions..$^{5 j, 14}$ Indirect evidence for this assumption is the successful synthesis of the 3D MOF 5, for which the analogous DPNI structure could not be prepared. ${ }^{19}$ A noteworthy feature of the reactions is the good crystal quality of the products. Consequently, we were able to characterize some of the products by single crystal XRD.

The possibility to use the SALE technique for synthesizing MOFs containing metal cages offers an interesting perspective for future developments. Boronate-ester capped clathrochelates are not only known for $\mathrm{Fe}^{\prime \prime}$, but also for $\mathrm{Fe}^{\mathrm{l}}, \mathrm{Co}^{\prime}, \mathrm{Co}^{\prime \prime}, \mathrm{Co}^{\prime \prime \prime}$, and $\mathrm{Ru}^{\prime \prime}$. 10,20 
The method might therefore be used as a simple way to prepare heterometallic ${ }^{21}$ and redox-active MOFs. ${ }^{22}$ Furthermore, the lateral groups on the cage complex can be varied substantially. ${ }^{10}$ For the present study, we have used four different cage structures, including chiral $\mathbf{2} \mathbf{d}$, but more variations can be envisioned. It might also be possible to incorporate cages with dichloroglyoximate ligands, which could be used for postsynthetic modifications via nucleophilic substitution reactions. ${ }^{10,23}$

\section{ASSOCIATED CONTENT}

Supporting Information. Experimental procedures and analytical data. This material is available free of charge via the Internet at http://pubs.acs.org.

\section{AUTHOR INFORMATION}

Corresponding Author

*(K.S) kay.severin@epfl.ch

\section{Author Contributions}

O.M.P. synthesized and characterized the compounds, P.S. performed the powder XRD analyses, J.B. contributed to the synthesis of metalloligand 2 d, F.F.-T. and R.S. carried out the single crystal XRD analyses, and K.S. initiated and coordinated the study / The manuscript was written through contributions of all authors. / All authors have given approval to the final version of the manuscript.

\section{Funding Sources}

Swiss National Science Foundation

\section{Notes}

The authors declare no competing financial interest.

\section{ACKNOWLEDGMENT}

The work was supported by the Swiss National Science Foundation (Project 200020_181974), and by the Ecole Polytechnique Fédérale de Lausanne (EPFL).

\section{REFERENCES}

(1) a) Yin, Z.; Wan, S.; Yang, J.; Kurmoo, M.; Zeng, M.-H. Recent advances in post-synthetic modification of metal-organic frameworks: New types and tandem reactions. Coord. Chem. Rev. 2019, 378, 500-512; b) Cohen, S. M. The Postsynthetic Renaissance in Porous Solids. J. Am. Chem. Soc. 2017, 139, 2855-2863; c) Cohen, S. M. Postsynthetic Methods for the Functionalization of Metal-Organic Frameworks. Chem. Rev. 2012, 112, 970-1000; d) Tanabe, K. K.; Cohen, S. M. Postsynthetic modification of metal-organic frameworks--a progress report. Chem. Soc. Rev. 2011, 40, 498-519; e) Wang, Z.; Cohen, S. M. Postsynthetic modification of metal-organic frameworks. Chem. Soc. Rev. 2009, 38, 1315-1329.

(2) a) Cui, O.; Wang, O.; Zhao, Y.; Sun, W.-Y. Fabrication of Desired Metal-Organic Frameworks via Postsynthetic Exchange and Sequential Linker Installation. Cryst. Growth Des. 2019, 19, 1454-1470; b) Karagiaridi, O.; Bury, W.; Mondloch, J. E.; Hupp, J. T.; Farha, O. K. Solvent-assisted linker exchange: an alternative to the de novo synthesis of unattainable metal-organic frameworks. Angew. Chem. Int.
Ed. 2014, 53, 4530-4540; c) Deria, P.; Mondloch, J. E.; Karagiaridi, O.; Bury, W.; Hupp, J. T.; Farha, O. K. Beyond postsynthesis modification: evolution of metal-organic frameworks via building block replacement. Chem. Soc. Rev. 2014, 43, 5896-5912; d) Han, Y.; Li, J.-R.; Guo, G. Substitution reactions in metal-organic frameworks and metal-organic polyhedral. Chem. Soc. Rev. 2014, 43, 5952-5981.

(3) Instead of linker replacement, it is also possible to install additional linkers in MOFs. For a review, see: Q. Pang, B. Tu, Q. Li. New linker installation in metal-organic frameworks. Dalton Trans. 2019, 48, 12000-12008.

(4) Burnett, B. J.; Barron, P. M.; Hu, C.; Choe, W. Stepwise synthesis of Metal-Organic Frameworks: Replacement of Structural Organic Linkers. J. Am. Chem. Soc. 2011, 133, 99849987.

(5) For examples, see: a) Danowski, W.; Van Leeuwen, T.; Abdolahzadeh, S.; Roke, D.; Browne, W. R.; Wezenberg, S. J.; Feringa, B. L. Unidirectional rotary motion in a metal-organic framework. Nature Nanotech. 2019, 14, 480-494; b) Cao, L.-H.; Liu, X.; Tang, X.-H.; Liu, J.; Xu, X.-Q.; Zang, S.-Q.; Ma, Y.-M. A Fivefold Linker Length Reduction in an Interpenetrated Metal-Organic Framework via Sequential SolventAssisted Linker Exchange. Chem. Commun. 2019, 55, 12671-12674; c) Gharib, M.; Esrafili, L.; Morsali, A.; Retailleau, P. Solvent-assisted ligand exchange (SALE) for the enhancement of epoxide ring-opening reaction catalysis based on three amide-functionalized metal-organic frameworks. Dalton Trans. 2019, 48, 8803-8814; d) Razavi, S. A. A.; Morsali, A. Ultrasonic-Assisted Linker Exchange (USALE): A Novel Post-Synthesis Method for Controlling the Functionality, Porosity, and Morphology of MOFs. Chem. Eur. J. 2019, 25, 10876-10885; e) Shao, Z.; Huang, C.; Dang, J.; Wu, Q.; Liu, Y.; Ding, J.; Hou, H. Modulation of Magnetic Behavior and $\mathrm{Hg}^{2+}$ Removal by Solvent-Assisted Linker Exchange Based on a Water-Stable 3D MOF. Chem. Mater. 2018, 30, 7979-7987; f) Xiao, G.-W.; Chen, T.-F.; Sun, X.-Z.; Guo, H.; Li, Z.-F.; Deng, Y.-H.; Wan, C.-Q. A route to robust thioetherfunctionalized MOF solid materials displaying heavy metal uptake and the ability to be further oxidized. Dalton Trans. 2017, 46, 12036-12040; f) Shin, S.; Jeong, S.; Kim, D.; Lah, M. S. Reversible Single-Crystal-to-Single-Crystal Transformations of Metal-Organic Frameworks that Accompany Two-Dimensional Framework Reorganizations. Cryst. Growth Des. 2017, 17, 2228-2237; g) Xu, Y.; Vermeulen, N. A.; Liu, Y.; Hupp, J. T.; Farha, O. K. SALE-Ing a MOF-Based "Ship of Theseus." Sequential Building-Block Replacement for Complete Reformulation of a Pillared-Paddlewheel Metal-Organic Framework. Eur. J. Inorg. Chem. 2016, 43454348; h) So, M. C.; Beyzavi, M. H.; Sawhney, R.; Shekhah, O.; Eddaoudi, M.; Al-Juaid, S. S.; Hupp, J. T.; Farha, O. K. PostAssembly Transformations of Porphyrin-Containing MetalOrganic Framework (MOF) Films Fabricated via Automated Layer-by-Layer Coordination. Chem. Commun. 2015, 51, 8588; i) Jeong, S.; Kim, D.; Song, X.; Choi, M.; Park, N.; Lah, M. S. Postsynthetic Exchanges of the Pillaring Ligand in ThreeDimensional Metal-Organic Frameworks. Chem. Mater. 2013, 25, 1047-1054; j) Karagiaridi, O.; Bury, W.; Tylianakis, E.; Sarjeant, A. A.; Hupp, J. T.; Farha, O. K. Opening MetalOrganic Frameworks Vol. 2: Inserting Longer Pillars into Pillared-Paddlewheel Structures through Solvent-Assisted Linker Exchange. Chem. Mater. 2013, 25, 3499-3503; k) Bury, W.; Fairen-Jimenez, D.; Lalonde, M. B.; Snurr, R. Q.; Farha, O. K.; Hupp, J. T. Control over Catenation in Pillared 
Paddlewheel Metal-Organic Framework Materials via Solvent-Assisted Linker Exchange. Chem. Mater. 2013, 25, 739744; I) Vermeulen, N. A.; Karagiaridi, O.; Sarjeant, A. A.; Stern, C. L.; Hupp, J. T.; Farha, O. K.; Stoddart, J. F. Aromatizing Olefin Metathesis by Ligand Isolation inside a MetalOrganic Framework. J. Am. Chem. Soc. 2013, 135, 1491614919.

(6) For incorporation of metalloligands with pyridyl donor groups, see: a) Xi, W.; Liu, Y.; Xia, Q.; Li, Z.; Cui, Y. Direct and Post-Synthesis Incorporation of Chiral Metallosalen Catalysts into Metal-Organic Frameworks for Asymmetric Organic Transformations. Chem. Eur. J. 2015, 21, 1258112585; b) Madrahimov, S. T.; Atesin, T. A.; Karagiaridi, O.; Sarjeant, A. A.; Farha, O. K.; Hupp, J. T.; Nguyen, S. T. Metalorganic frameworks containing (alkynyl)gold functionalities: A comparative evaluation of solvent-assisted linker exchange, de novo synthesis, and post-synthesis modification. Cryst. Growth Des. 2014, 14, 6320-6324; c) Takaishi, S.; DeMarco, E. J.; Pellin, M. J.; Farha, O. K.; Hupp, J. T. Solventassisted linker exchange (SALE) and post-assembly metallation in porphyrinic metal-organic framework materials. Chem. Sci. 2013, 4, 1509-1513.

(7) For examples, see: a) Zhang, X.; Sun, J.; Wei, G.; Liu, Z.; Yang, H.; Wang, K.; Fei, H. In Situ Generation of an N-Heterocyclic Carbene Functionalized Metal-Organic Framework by Postsynthetic Ligand Exchange: Efficient and Selective Hydrosilylation of CO2. Angew. Chem. Int. Ed. 2019, 59, 28442849; b) Tan, C.; Han, X.; Li, Z.; Liu, Y.; Cui, Y. Boosting Chemical Stability, Catalytic Activity, and Enantioselectivity of Metal-Organic Frameworks for Batch and Flow Reactions. J. Am. Chem. Soc. 2019, 140, 16229-16236; c) Zhao, S.-S.; Zhang, H.; Wang, L.; Chen, L.; Xie, Z. Facile preparation of a tetraphenylethylene-doped metal-organic framework for white light-emitting diodes. J. Mater. Chem. C 2018, 6, 11701-11706; d) Han, S.-Y.; Pan, D.-L.; Chen, H.; Bu, X.-B.; Gao, Y.-X.; Gao, H.; Tian, Y.; Li, G.-S.; Wang, G.; Cao, S.-L.; Wan, C.-Q; Guo, G.-C. A Methylthio-Functionalized-MOF Photocatalyst with High Performance for Visible-LightDriven $\mathrm{H}_{2}$ Evolution. Angew. Chem. Int. Ed. 2018, 57, 98649869; e) Miera, G. G.; Gómez, A. B.; Chupas, P. J.; MartínMatute, B.; Chapman, K. W.; Platero-Prats, A. E. Topological Transformation of a Metal-Organic Framework Triggered by Ligand Exchange. Inorg. Chem. 2017, 56, 4576-4583; f) Liu, C.; Zeng, C.; Luo, T.-Y.; Merg, A. D.; Jin, R.; Rosi, N. L. Establishing Porosity Gradients within Metal-Organic Frameworks Using Partial Postsynthetic Ligand Exchange. J. Am. Chem. Soc. 2016, 138, 12045-12048; g) Wang, W.; Wang, L.; Li, Z.; Xie, Z. BODIPY-containing nanoscale metalorganic frameworks for photodynamic therapy. Chem. Commun. 2016, 52, 5402-5405; h) Li, T.; Kozlowski, M. T.; Doud, E. A.; Blakely, M. N.; Rosi, N. L. Stepwise ligand exchange for the preparation of a family of mesoporous MOFs. J. Am. Chem. Soc. 2013 135, 11688-11691; i) Kim, M.; Cahill, J. F.; Fei, H.; Prather, K. A.; Cohen, S. M. Postsynthetic ligand and cation exchange in robust metal-organic frameworks. J. Am. Chem. Soc. 2012, 134, 18082-18088.

(8) For examples, see: a) Tsai, C.-W.; Niemantsverdriet, J. W.; Langner, E. H. G. Enhanced $\mathrm{CO}_{2}$ adsorption in nano-ZIF-8 modified by solvent assisted ligand exchange. Micropor. Mesopor. Mater. 2018, 262, 98-105; b) Lalonde, M. B.; Mondloch, J. E.; Deria, P.; Sarjeant, A. A.; Al-Juaid, S. S.; Osman, O. I.; Farha, O. K.; Hupp, J. T. Selective Solvent-Assisted Linker Exchange (SALE) in a Series of Zeolitic Imidazolate
Frameworks. Inorg. Chem. 2015, 54, 7142-7144; c) Schweinefuß, M. E.; Springer, S.; Baburin, I. A.; Hikov, T.; Huber, K.; Leoni, S.; Wiebcke, M. Zeolitic imidazolate framework-71 nanocrystals and a novel SOD-type polymorph: solution mediated phase transformations, phase selection via coordination modulation and a density functional theory derived energy landscape. Dalton Trans. 2014, 3528-3536; d) Fei, H.; Cahill, J. F.; Prather, K. A.; Cohen, S. M. Tandem postsynthetic metal ion and ligand exchange in zeolitic imidazolate frameworks. Inorg. Chem. 2013, 52, 4011-4016; e) Karagiaridi,O.; Lalonde, M. B.; Bury, W.; Sarjeant, A. A.; Farha, O. K.; Hupp, J. T. Opening ZIF-8: a catalytically active zeolitic imidazolate framework of sodalite topology with unsubstituted linkers. J. Am. Chem. Soc. 2012, 134, 1879018796.

(9) a) Erkatal, M.; Erkilic, U.; Tam, B.; Usta, H.; Yazaydin, O.; Hupp, J. T.; Farha, O. K.; Sen, U. From 2-methylimidazole to 1,2,3-triazole: a topological transformation of ZIF-8 and ZIF67 by post-synthetic modification. Chem. Commun. 2017, 53, 2028-2031; b) Jiang, J.-Q.; Yang, C.-X.; Yan, X.-P. Postsynthetic ligand exchange for the synthesis of benzotriazole-containing zeolitic imidazolate framework. Chem. Commun. 2015, 51, 6540-6543.

(10) a) Voloshin, Y. Z.; Belaya, I. G.; Krämer, R. K. Cage Metal Complexes; Clathrochelates Revisited; Springer International Publishing: New York, United States, 2017; b) Voloshin, Y. Z.; Kostromina, N. A.; Krämer, R. K.: Clathrochelates: Synthesis, Structure and Properties; Elsevier Science: Amsterdam, The Netherlands, 2002.

(11) Jansze, S. M.; Severin, K. Clathrochelate Metalloligands in Supramolecular Chemistry and Materials Science. Acc. Chem. Res. 2018, 51, 2139-2147.

(12) a) Jansze, S. M.; Ortiz, O.; Fadei Tirani, F.; Scopelliti, R.; Menin, L.; Severin, K. Inflating Face-Capped $\mathrm{Pd}_{6} \mathrm{~L}_{8}$ Coordination Cages. Chem. Commun. 2018, 54, 9529-9532; b) Cecot, G.; Marmier, M.; Geremia, S.; De Zorzi, R.; Vologzhanina, A. V.; Pattison, P.; Solari, E.; Fadaei Tirani, F.; Scopelliti, R.; Severin, K. The Intricate Structural Chemistry of $\mathrm{M}^{\prime \prime}{ }_{2 n} \mathrm{~L}_{n}$-Type Assemblies. J. Am. Chem. Soc. 2017, 139, 8371-8381; c) Jansze, S. M.; Wise, M. D.; Vologzhanina, A. V.; Scopelliti, R.; Severin, K. Pd" ${ }_{2} \mathrm{~L}_{4}$-type coordination cages up to three nanometers in size. Chem. Sci. 2017, 8, 1901-1908; d) Jansze, S. M.; Cecot, G.; Wise, M. D.; Zhurov, K. O.; Ronson, T. K.; Castilla, A. M.; Finelli, A.; Pattison, P.; Solari, E.; Scopelliti, R.; Zelinskii, G. E.; Vologzhanina, A. V.; Voloshin, Y. Z.; Nitschke, J. R.; Severin, K. Ligand Aspect Ratio as a Decisive Factor for the Self-Assembly of Coordination Cages. J. Am. Chem. Soc. 2016, 138, 2046-2054; e) Cecot, G.; Alameddine, B.; Prior, S.; Zorzi, R. D.; Geremia, S.; Scopelliti, R.; Fadaei, F. T.; Solari, E.; Severin, K. Large heterometallic coordination cages with gyrobifastigium-like geometry. Chem. Commun. 2016, 52, 11243-11246; f) Ardavan, A.; Bowen, A. M.; Fernandez, A.; Fielding, A. J.; Kaminski, D.; Moro, F.; Muryn, C. A.; Wise, M. D.; Ruggi, A.; Mclnnes, E. J. L.; Severin, K.; Timco, G. A.; Timmel, C. R.; Tuna, F.; Whitehead, G. F. S.; Winpenny, R. E. $P$. Engineering coherent interactions in molecular nanomagnet dimers. Npj Quantum Information 2015, 1 , 15012; g) Wise, M. D.; Holstein, J. J.; Pattison, P.; Besnard, C.; Solari, E.; Scopelliti, R.; Bricogne, G.; Severin, K. Large, heterometallic coordination cages based on ditopic metalloligands with 3-pyridyl donor groups. Chem. Sci. 2015, 6, 1004-1010. 
(13) Pascu, M.; Marmier, M.; Schouwey, C.; Scopelliti, R.; Holstein, J. J.; Bricogne, G.; Severin, K. Anionic bipyridyl ligands for applications in metallasupramolecular chemistry. Chem. Eur. J. 2014, 20, 5592-5600.

(14) Jansze, S. M.; Severin, K. Palladium-Based Metal-Ligand Assemblies: The Contrasting Behavior upon Addition of Pyridine or Acid. J. Am. Chem. Soc. 2019, 141, 815-819.

(15) Farha, O. K.; Malliakas, C. D.; Kanatzidis, M. G.; Hupp, J. T. Control over Catenation in Metal-Organic Frameworks via Rational Design of the Organic Building Block J. Am. Chem. Soc. 2010, 132, 950-952.

(16) Bila, J. L.; Pijeat, J.; Ramorini, A.; Fadaei-Tirani, F., Scopelliti, R.; Baudat, E.; Severin, K. Porous networks based in iron(II) clathrochelate complexes. Dalton Trans. 2019, 48, 45824588.

(17) Chung, H.; Barron, P. M.; Novotny, R. W.; Son, H.-T.; Hu, C.; Choe, W. Structural Variation in Porphyrin Pillared Homologous Series: Influence of Distinct Coordination Centers for Pillars on Framework Topology. Cryst. Growth Des. 2009, 9, 3327-3332.

(18) As in the case of $\mathbf{3}$, a direct synthesis under solvothermal conditions was not successful.

(19) Burnett, B. J.; Choe, W. Stepwise pillar insertion into metalorganic frameworks: a sequential self-assembly approach. CrystEngComm. 2012, 14, 6129-6131.

(20) For examples, see: a) Voloshin, Y. Z.; Novikov, V. V.; NeIyubina, Y. V.; Belov, A. S.; Roitershtein, D. M.; Savitsky, A.; Mokhir, A.; Sutter, J.; Miehlich, M. E.; Meyer, K. Synthesis and characterization of an $\mathrm{Fe}(\mathrm{I})$ cage complex with high stability towards strong H-acids. Chem. Commun. 2018, 54,
3436-3439; b) Nguyen, M. T. D.; Charlot, M.-F.; Aukauloo, A. Strictural, Elecronic, and Theoretical Description of a Series of Cobalt Clathrochelate Complexes in the $\mathrm{Co}$ (III), $\mathrm{Co}$ (II) and Co(I) Oxidation Sates. J. Phys. Chem. A 2011, 115, 911922; c) Liu, W.; Huang, W.; Pink, M.; Lee, D. Layer-by-Layer Synthesis of Metal-Containing Conducting Polymers: Caged Metal Centers for Interlayer Charge Transport. J. Am. Chem. Soc. 2010, 132, 11844-11846; d) Voloshin, Y. Z.; Varzatskii, O. A.; Novikov, V. N.; Strizhakova, N. G.; Vorontsov, I. I.; Vologzhanina, A. V.; Lyssenko, K. A.; Romanenko, G. V.; Fedin, M. V.; Ovcharenko, V. I.; Bubnov, Y. N. Tris-Dioximate Cobalt(I,IIIII) Clathrochelates: Stabilization of Different Oxidation and Spin States of an Encapsulated Metal Ion by Ribbed Functionalization. Eur. J. Inorg. Chem. 2010, 5401-5415; e) Muller, J. G.; Grzybowski, J. J.; Takeuchi, K. J. Synthesis and Characterization of a Ruthenium(II) Clathrochelate Complex. Inorg. Chem. 1986, 25, 2665-2667.

(21) Masoomi, M. Y.; Morsali, A.; Dhakshinamoorthy, A.; Garcia, H. Mixed-Metal MOFs: Unique Opportunities in Metal-Organic Framework (MOF) Functionality and Design. Angew. Chem. Int. Ed. 2019, 58, 15188-15205.

(22) Calbo, J.; Golomb, M. J.; Walsh, A. Redox-active metal-organic frameworks for energy conversion ad storage. J. Mater. Chem. A 2019, 7, 16571-16579.

(23) Zelinskii, G. E.; Belov, A. S.; Vologzhanina, A. V.; Limarev, I. P.; Dorovatovskii, P. V.; Zubavichus, Y. V.; Lebed, E. G.; VoIoshin, Y. Z.; Dedov, A. G. Molecular design and structural peculiarities of the 3- and 4-pyridylboron-capped tris-glyoximat and tris-dichloroglyoximate iron(II) clathrochelates with apical donor groups. Polyhedron 2019, 160, 108-114. 
Graphical Abstract:

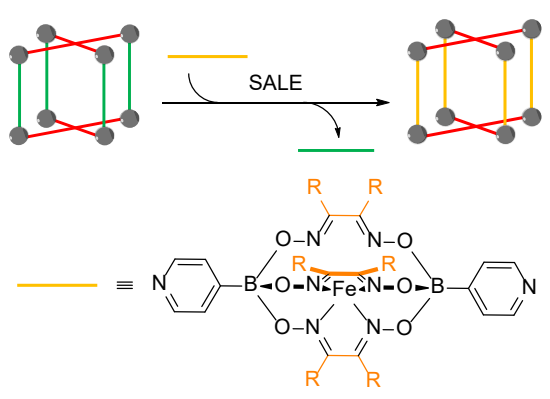

Metal-organic frameworks containing iron(II) cage complexes were obtained by solvent-assisted ligand exchange. 